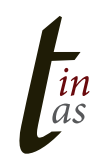

Tintas. Quaderni di letterature iberiche e iberoamericane, 10 (2021), pp. 33-44. ISSN: 2240-5437.

http://riviste.unimi.it/index.php/tintas

\title{
Hermandad y reescritura del mito de Isis y Osiris en la literatura española contemporánea
}

\author{
María Teresa Navarrete \\ Uppsala Universitet \\ mariateresa.navarretenavarrete@moderna.uu.se
}

\section{INTRODUCCIón}

Para la cultura occidental, el mito de Isis y Osiris ha sido el más inspirador de la mitología egipcia. Lucio invoca a Isis para volver a tener forma humana en El asno de oro y también Mozart compone el aria «O, Isis und Osiris» para el rito de iniciación de Pamina y Tamino en Die Zauberflöte. Menciono solo dos de los muchos ejemplos que se podrían señalar para distinguir en el mito de Isis y Osiris un relato acumulativo que atesora versiones provenientes de épocas, géneros artísticos y perspectivas disímiles.

En este caso, este artículo dirige el foco de análisis a la figura femenina, Isis, y a la forma en la que la literatura española contemporánea ha reformulado su participación en el mito. Para ello, he seleccionado «Balada de un día de julio» (1921) de Federico García Lorca (1898-1936), «Pantomima» (1995) de Manuel Mantero (1930-) y El hechizo de Iris (1999) de José María Merino (1941-). La elección de estas tres obras está motivada por la pertenencia de sus autores a tres generaciones literarias e históricas distintas: Federico García Lorca, adscrito a la generación del 27, Manuel Mantero, perteneciente a la generación de los niños de la guerra civil española, y José María Merino, nacido en la posguerra española y cuya producción literaria se publica plenamente en Democracia.

A pesar de estas diferencias, en estas obras se aprecian ciertas similitudes en el tratamiento que estos textos realizan de la figura de Isis. Tradicionalmente, Isis simboliza la fertilidad, la agricultura, la civilización y las leyes. Pero, en estos textos, Isis no aparece únicamente como una diosa caracterizada por inducir la trasmutación, provocar la resurrección o devolver la fertilidad. La lectura contemporánea del mito pone el énfasis en la voluntad de unión con Osiris que Isis consigue cumplir, a pesar de los obstáculos iniciales -muerte y desmembración- que la impiden. Por ello, mi propósito en esta investigación es analizar la manera en la que el mito de Isis y Osiris aparece como paradigma o modelo de hermandad en los textos literarios españoles anteriormente citados. Para este fin, me serviré, especialmente, de herramientas procedentes de la mitocrítica como el mitema y de métodos propuestos por el mitoanálisis, preferentemente los formulados por Gilbert Durand y Pierre Brunel, aunque también utilizaré reflexiones y conceptos sobre el mito 
que provienen de los trabajos de Karl Gustav Jung, Michael Riffaterre y Jean François Lyotard, y sobre la intertextualidad acogiendo los análisis de Gérard Genette ${ }^{1}$.

\section{EL MITO DE ISIS Y OSIRIS}

Antes de comenzar el análisis del proceso de reescritura que Federico García Lorca, Manuel Mantero y José María Merino emprenden del mito de Isis y Osiris, comentaré brevemente las etapas del mito egipcio con la intención de señalar la doble relación entre sus protagonistas, por un lado, fraterna y, por otro, matrimonial, aunque esta última no estaba presente en las versiones más antiguas de la leyenda de Osiris. Isis forma parte del conjunto de dioses formado por Geb, la Tierra, y Nut, el Cielo, y sus descendientes, Osiris, Set, Neftis y la propia Osiris. Tanto en los Textos de las pirámides, versión escrita más antigua de la leyenda ${ }^{2}$, como en la Estela de Ikhernofret ${ }^{3}$, Isis era simplemente la hermana de Osiris y no jugaba un papel tan dominante. Fue en el Imperio Nuevo (c. 1580-1086 a. J.C.), etapa en la que el culto al dios incrementa su popularidad y significado, cuando la leyenda se sistematiza e Isis se convierte en la protagonista de la mayoría de los episodios del mito. Además de figurar como la hermana de Osiris, aparece también como la esposa del dios ${ }^{4}$. Y, desde el siglo IV a. J.C., dominan en su iconografía las habilidades mágicas, la capacidad para llevar a buen término peregrinajes y la función mediadora en trances difíciles e incluso en el paso de la vida a la resurrección en el Más Allá.

Para señalar las etapas del mito, me serviré de la versión de Plutarco incluida en Obras morales y costumbres. Plutarco recoge la versión ya sistematizada de la leyenda y ofrece la versión completa que se conserva del relato. En ella se distinguen ocho etapas: 1) Nacimientos divinos; 2) El reino terrestre de Osiris; 3) El asesinato de Osiris; 4) El duelo y la primera búsqueda de Osiris; 5) El hallazgo de Osiris en Biblos; 6) La vuelta de Biblos y el nacimiento de Horus; 7) El desmembramiento y el entierro de Osiris; 8) La venganza de Horus, derrota y juicio de Seth ${ }^{6}$.

${ }^{1}$ Lévi-Strauss, Claude, Myth and meaning, Toronto, University of Toronto, 1978; Durand, Gilbert. De la mitocrítica al mitoanálisis: figuras míticas y aspectos de la obra, Barcelona, Anthropos, 1993; Mitos y sociedades. Introducción a la mitología, Buenos Aires, Editorial Biblos, 2003; Brunel, Pierre (dir.), Dictionnaire des mythes littéraires, Éditions du Rocher, Bertrand, 1988, p. 786; Mythocritique. Théorie et parcours, París, Presses Universitaires de France, 1992; Jung, Carl Gustav, Símbolos de transformación, Barcelona, Paidós, 2005; Arquetipos e inconsciente colectivos, Barcelona, Paidós, 2009; Riffaterre, Michael, «Sémiotique intertextuelle: l'interprétant», Revue d'esthétique, 1-2 (1979), pp. 128-150; Jean François Lyotard, The inhuman. Reflections on Time, California, Standford University Press, 2008; Gérard Genette, Palimpsestes. La Littérature au second degré, París, Éditions du Seuil, 1992.

${ }^{2}$ Faulkner, Raymond O., The ancient Egyptian pyramid texts, Oxford, Clarendon Press, 1969.

${ }^{3}$ Lichtheim, Miriam, Ancient Egyptian literature. A book of readings 1, Berkeley, University of California Press, 1973, p. 123.

${ }^{4}$ Fernández Delgado, José Antonio y Pordomingo Pardo, Francisca, «Introducción», en Plutarco, Obras morales y de costumbres (Moralia) 6, Madrid, Gredos, 1995, pp. 14-17.

${ }^{5}$ García Gual, Carlos, Diccionario de mitos, Barcelona, Planeta, 1997, pp. 208-210.

${ }^{6}$ Plutarco, op. cit., pp. 78-82, \$12, 355D-356a; pp. 82-83, \$12, 356A-B; pp. 83-84, \$13, 356B-D; pp. 84-86, $\$ 14$, 356D-F; pp. 86-89, \$15-16, 357A-D; pp. 89-90, §16-17; 357D; pp. 90-93, \$18, 357F-358B; pp. 93-96, $\$ 19,358 \mathrm{~B}-\mathrm{E}$. 
Este es el mito literarizado ${ }^{7}$ - «mito reelaborado dentro de un texto literario» ${ }^{8}$ - por Plutarco donde se perciben varios rasgos helenizantes que acercan el mito de Isis y Osiris al de Deméter y Perséfone 9 . De Plutarco también deriva la definición de Isis como «fille du ciel et de la terre, issue du dieu-soleil», que simboliza la fertilidad, la agricultura, la civilización y las leyes ${ }^{10}$. Aún así, se convierte en la referencia más frecuente en futuras elaboraciones de Isis y Osiris, aunque también existen otras anteriores como la ofrecida en los Textos de las Pirámides que persisten, como veremos más adelante, como punto de partida en algunas reescrituras contemporáneas.

A pesar de que estas dos versiones muestran variantes en algunos de sus pasajes, ambas se organizan en un universo sistémico ${ }^{11}$ o dilemático ${ }^{12}$ en el que la «tensión antagonista» entre Osiris y Seth vertebra el relato ${ }^{13}$. Sin embargo, a medida que el mito se desarrolla, proliferan otras antítesis que se repiten de manera reiterada en cada una de las referencias tópicas del mito: dispersión/unión, esterilidad/fertilidad o muerte/vida. Este material redundante, que persiste a pesar de las modulaciones que se lleven a cabo en las distintas versiones o reescrituras del mito, fue acogido por Claude Lévi-Strauss bajo el término mitema ${ }^{14}$. Los mitemas representan, según su definición, las unidades mínimas de significado de los mitos que consiguen vertebrarlos y hacerlos reconocibles cuando son enunciados, con indiferencia del universo artístico en el que se inserten. De acuerdo con Gilbert Durand, la transmutación se percibe como el mitema predominante en el mito de Isis y Osiris, siguiendo la estela de otras leyendas de Egipto en las que la muerte se contempla a modo de «un segundo nacimiento» ${ }^{15}$.

\section{3. «BALAdA DE UN díA dE JULIO» DE FEDERICo GARCÍA LoRCA}

El análisis sobre la presencia del mito clásico en la poesía de Federico García Lorca ha gozado de gran atención por parte de la crítica. Entre los muchos trabajos desarrollados, merece especial atención el volumen colectivo editado por José María Camacho Rojo, Estudios sobre la tradición clásica en la obra de Federico García Lorca, en el que participan críticos con una considerable trayectoria de investigación sobre este tópico como Rosa María Aguilar o Antonia Carmona ${ }^{16}$. Sin embargo, en estos trabajos la clave mitológica

\footnotetext{
${ }^{7}$ Siganos, André, Le Minotaure et son mythe, Paris, Presses Universitaires, 1993, p. 32.

${ }^{8}$ Herrero Cecilia, Juan, «El mito como intertexto: la reescritura de los mitos en las obras literarias», Çedille. Revista de estudios franceses, 2 (2006), p. 65.

${ }_{9}^{9}$ Pecci Tenrero, Hipólito, «Isis, la Gran Maga», Espacio, tiempo y forma, 15 (2004), p. 17; Santamaría Canales, Israel, «Isis a través de los textos: el culto isíaco en la literatura grecolatina de época imperial», Ilu. Revista de ciencias de la religiones, 20 (2015), p. 236.

${ }^{10}$ Brunel, Pierre, Dictionnaire des mythes littéraires, p. 786.

${ }^{11}$ Durand, Gilbert, Mitos y sociedades, pp. 154-155.

${ }^{12}$ Lévi-Strauss, Claude, Myth and meaning, p. 191.

${ }^{13}$ Durand, Gilbert, De la mitocrítica al mitoanálisis, p. 29.

${ }^{14}$ Véase Lévi-Strauss, Claude, op. cit.

${ }^{15}$ Durand, Gilbert, De la mitocrítica al mitoanálisis, p. 238.

${ }^{16}$ Camacho Rojo, José María (ed.), La tradición clásica en la obra de Federico García Lorca, Granada, Universidad de Granada, 2006; Aguilar Fernández, Rosa María, «El mito griego en la poesía de García Lorca», Cuadernos de filología clásica: estudios griegos e indoeuropeos, 8 (1998), pp. 75-102; Carmona, Antonia, «Elementos míticos en el teatro de Eurípides y Federico García Lorca», Calamus Renascens: revista
} 
se desarrolla en el terreno grecolatino y, de acuerdo con Ángel Álvarez de Miranda, en el universo lorquiano también aparecen mitos de antiguas religiones, entre los que se versan aquellos que proceden de la tradición egipcia. Aún más, Álvarez de Miranda mantiene que los mitos en la obra lorquiana «brotan de un mismo sistema de intuiciones sobre la sacralidad de la vida orgánica» que puede resumirse en tres trances, «vivir, engendrar y morir», todos ellos congregados en el mito egipcio de Isis y Osiris y que Federico García Lorca acoge tempranamente en «Balada de un día de julio» de Libro de poemas (1919-1921) ${ }^{17}$.

En este poema, el mito de Isis y Osiris se acoge únicamente desde un acontecimiento de la cuarta etapa propuesta por Plutarco, la búsqueda de Osiris por parte de Isis. En la versión de Plutarco, se hace referencia a una Isis con «un vestido de luto» $\mathrm{y}$ "errante por todas partes y sin salida, a nadie a quien se acercaba dejaba de preguntar» ${ }^{18}$. "Balada de un día de julio», al igual que en esta versión, también presenta al personaje femenino enlutado $-\ll-i$ Por qué llevas un manto / negro de muerte? / -¡Ay, soy la viudita / triste y sin bienes!»- y en busca del cuerpo de su amado - «Busco el cuerpo del conde / de los Laureles»- ${ }^{19}$. El poema de Lorca adopta la estructura dialogada de la canción infantil y ofrece el diálogo que Plutarco elide. Pero, a diferencia de lo que ocurre en el texto de Plutarco, Isis no aparece interrogando a todo aquel que se encuentra a su paso, sino que es el personaje interrogado. Bastan los primeros versos del poema de Lorca para advertir esta nueva dinámica: «-¿Dónde vas, niña mía, / de sol y de nieve? / -Voy a las margaritas / del prado verde». A medida que avanzan las preguntas, el personaje femenino va revelando sus atributos, hasta que su interlocutor declara: «-Ah, Isis soñadora» ${ }^{20}$.

La aparición de Isis en el poema ha sido acogida por la crítica de forma desigual. Para Candelas Newton, la incorporación de Isis funciona como una referencia sin efecto en el contenido global de la pieza. La caracterización del personaje femenino como «Isis soñadora» no es más que una forma de aludir a que esta "aún espera encontrar de algún modo el amor» ${ }^{21}$. Esta interpretación llevó a que años más tarde, Natalia Arséntieva se replantease la función de este personaje en el poema. Para Arséntieva, «el pathos de la balada es totalmente distinto»:

El poeta admira la ilusión de la joven viuda de encontrar a su amante «que vive y muere», acudiendo a la ilusión mitológica: al igual que ha encontrado la «Isis soñadora» el cuerpo descuartizado de su marido Osiris para resucitarlo, la niña «de sol y de nieve», es decir, de amor y angustia, se empeña en busca del cuerpo de su amante sin tener miedo. ${ }^{22}$

En este caso, Arséntieva contempla la búsqueda de la viudita como una equivalencia con el mito de Isis y Osiris, planteamiento que, según mi lectura, se refuerza con la

de humanismo y tradición clásica, 2 (2001), pp. 23-41, y Coincidencias de lo trágico entre Eurípides y Federico García Lorca, Alcañiz, Madrid, Ediciones del Laberinto, 2003.

${ }^{17}$ Álvarez de Miranda, Ángel, La metáfora y el mito, Madrid, Ediciones Taurus, 1963, pp. 12-13.

${ }^{18}$ Plutarco, op. cit., p. 85, $\$ 14365 \mathrm{E}$.

${ }^{19}$ García Lorca, Federico, Obras completas: poesía, Barcelona, Galaxia Gutenberg, 1997, pp. 107-108.

${ }^{20}$ Ibid., pp. 106-107.

${ }^{21}$ Newton, Candelas, Lorca, una escritura en trance: Libro de poemas y Diván del Tamarit, Amsterdam / Philadelphia, John Benjamins Publishing Company, 1992, p. 109.

${ }^{22}$ Arséntieva, Natalia, «Orígenes y estructura y principales aspectos de la cosmología mitopoética de García Lorca», en Camacho Rojo, José María (ed.), La tradición clásica en la obra de Federico García Lorca, Granada, Universidad de Granada, 2006, p. 305. 
presencia de otras similitudes, algunas ya señaladas, como la vestimenta de luto con la que se caracteriza a este personaje.

Siguiendo la línea apuntada por Arséntieva, una vez que se desvela la identidad de «la viudita»-«-Ah, Isis soñadora»-, este personaje empieza a comportarse de acuerdo con las pautas del mito. Adopta un rol activo en el diálogo y comienza a formular preguntas. En una de ellas se cuestiona por el paradero de su amante difunto, aquí interpelado con el término «Conde del Laurel»: «¿Dónde hallaré a mi amante / que vive y muere?» ${ }^{23}$. Esta intervención ofrece, además, una caracterización del amante difunto que se vincula con Osiris. Igual que en el mito egipcio, este personaje se sitúa entre la vida y la muerte y espera a que su amada lo encuentre. Ante la pregunta «-¿Dónde hallaré a mi amante / que vive y muere?», el interlocutor de la "viudita» en este poema, el caballero errante, responde: «-Está muerto en el agua» ${ }^{24}$. Estamos ante la primera vez que Federico García Lorca hace uso de la imagen del agua ${ }^{25}$. Y, aunque en Libro de poemas el universo simbólico lorquiano está todavía en construcción, su funcionalidad ya descansa en la dualidad y contribuye a trazar el espacio limítrofe entre la vida y la muerte en el que se sitúa el «Conde del Laurel».

Estas concomitancias advierten que la presencia del mito egipcio en esta pieza de Lorca no se limita a la alusión de Isis. Es cierto que el propósito de este poema no consiste en reescribir el mito al completo exponiendo su argumento de principio a fin, pero la aparición de Isis sí propicia que proliferen una serie de rasgos que crean una base estructural mítica sobre la que se sostiene el texto poético. Por un lado, una vez que se desvela la identidad de este personaje, Isis explicita su voluntad de búsqueda del amado y, por otro lado, la caracterización del Conde del Laurel, como amado perdido y alojado en un espacio entre la vida y la muerte, descansa sobre la figura de Osiris.

De este modo, junto a la influencia compositiva del folklore infantil, habría que sumar, por tanto, la del mito de Isis y Osiris que, una vez pasado por el filtro popular que envuelven estos primeros poemas de Lorca, se yergue como uno de los motores estructurales del texto. A diferencia de las lecturas apuntadas por Newton y Arséntieva, a mi juicio, en este poema tiene lugar un fenómeno de «émergence ${ }^{26}$, ya que, cuando el poema desvela la identidad de la viudita, emerge el mito de Isis y Osiris y se convierte en la guía explicativa del poema. En este punto, el relato mítico funciona a modo de ancla en el desarrollo del poema, lo que no impide ni opaca la presencia del universo estético lorquiano.

De este modo, si se contempla "Balada de un día de julio», a modo de actualización del mito dentro de las especificaciones de la poética lorquiana, este poema es susceptible de considerarse, según la terminología de Gérard Genette, como un hipertexto que reformula el relato del Isis y Osiris, entendido este último como el hipotexto ${ }^{27}$. Además, si se atiende a la relación de hipertextualidad que este poema mantiene con el relato de Isis y Osiris, se revela el origen creativo que sostiene la base argumental de esta pieza lírica. Contrariamente, si se obvia la referencia al mito, disminuye el alcance significativo de «Balada de un día de julio» y se resta trascendencia, en un primer lugar, a la búsqueda de la viudita y, en segundo lugar, a una primeriza configuración dual del símbolo del agua que ya se desarrolla a partir de la conjunción de la vida y de la muerte.

\footnotetext{
${ }^{23}$ García Lorca, Federico, op. cit., p. 108.

${ }^{24}$ Ibid.

${ }^{25}$ Tijeras, Eduardo, «Hacia García Lorca por las imágenes del agua», Cuadernos Hispanoamericanos, 433-434 (1986), p. 98.

${ }^{26}$ Brunel, Pierre, Mythocritique. Théorie et parcours, pp. 72-75.

${ }^{27}$ Genette, Gérard, op. cit., p. 13.
} 


\section{4. «Pantomima» de Manuel Mantero}

Los mitos que provienen del mundo grecolatino definen la lírica de Manuel Mantero, especialmente a partir de los poemarios Crates de Tebas y Memorias de Deucalión ${ }^{28}$. En estos libros, Mantero descubre «la actualidad del mundo clásico [...]» por su «perennidad del sentimiento ${ }^{29}$. Sobre la importancia del mito en su obra, Mantero escribió una nota al final de Memorias de Deucalión:

Cualquier aspecto del mito me interesa: el castigo del Diluvio por la abominación humana (canibalismo, que yo interpreto como la misma guerra), la invención del vino por Deucalión (hay alusiones al vino en más de un poema de este libro), pero me interesa en especial el tema de la creación o recreación del hombre por gracia concedida a Deucalión y Pirra. Lo que pasa es que yo traslado, en buena parte, la perspectiva a la creación de la palabra. ${ }^{30}$

En otros textos de corte ensayístico donde Mantero reflexiona sobre su propia poética, también ha declarado la importancia del mito en su obra y lo define como «la expresión universal, temporal y simbólica de un conflicto a través de la experiencia de un individuo ${ }^{31}$. A pesar de que estas manifestaciones teóricas sobre el mito se fechan en las décadas de los 80 y 90, etapa en la que la poesía de Mantero ha alcanzado la madurez, lo cierto es que desde el inicio de su obra se advierte una preferencia hacia el simbolismo y la introspección, esferas en las que la alegoría del mito permite a Mantero experimentar con la formulación del origen y la esencialidad ${ }^{32}$. Ese sesgo metafísico de la poesía de Mantero lo distingue de la estética social realista que caracterizó a la generación lírica del medio siglo a la que su trayectoria lírica se adscribe ${ }^{33}$.

El poemario Fiesta asume presupuestos líricos de los libros mencionados con anterioridad y prosigue el ejercicio de reescritura mítica en «Pantomima», poema que consideraré como objeto de mi estudio ${ }^{34}$. «Pantomima» acoge la leyenda de Isis y Osiris y, al igual que ocurre en «Balada de un día de julio», solo acoge una escena del mito. En este caso, se versifica el momento en el que Isis localiza a Osiris. La elección de este acontecimiento del mito no resulta extraño, ya que, al igual que ocurría con Deucalión, a Mantero le interesa del mito su poder de génesis y reinvención del hombre. Por ello, el mitema que Mantero distingue en Isis y Osiris se funda en el poder que posee Isis para regenerar a Osiris y engendrar a Horus:

Isis alta y delgada que se echa sobre Osiris por Isis desnudado,

\footnotetext{
${ }^{28}$ Mantero, Manuel, Crates de Tebas, Ferrol, Esquío, 1980; Memorias de Deucalión, Barcelona, Plaza \& Janés, 1982.

${ }^{29}$ Crespo, Ángel, «Ética y estética en la poesía de Manuel Mantero», Anthropos: Boletín de información $y$ documentación, 116 (1991), p. 41.

${ }^{30}$ Mantero, Manuel, Memorias de Deucalión, p. 130.

${ }^{31}$ Mantero, Manuel, «Autopercepción intelectual de un proceso histórico: autobiografía intelectual y cronología», Anthropos: Boletín de información y documentación, 116 (1991), p. 24.

32 Barnette, Douglas W., «Manuel Mantero y el proceso poético», Anthropos: Boletín de información y documentación, 116 (1991), pp. 27-31.

${ }^{33}$ Crespo, Ángel, op. cit., p. 39.

${ }^{34}$ Mantero, Manuel, Fiesta, Madrid, Endymion, 1995.
} 
doble blancura en la orilla del río y el cadáver de él, tibio, copulando, ella que sueña con un vástago de sol y de rabia, vengándola y vengándolo, él cubierto de un techo de sudores y embebido por labios subterráneos. Isis y Osiris que inventan la vida en la noche estrellada de verano ${ }^{35}$.

Si analizamos las relaciones de hipertextualidad que este poema de Mantero establece con las primeras versiones del mito, se observa su predilección por los Textos de las Pirámides frente a la obra de Plutarco. En el tratado de Plutarco, el encuentro entre Isis y Osiris queda referido, pero no se apuesta por destacar el carácter creador de Isis: «En el primer lugar solitario que encontró, a solas consigo misma abrió el arca y juntando rostro con rostro lo abrazaba y lloraba $»^{36}$. Lo escueto del relato lleva a Mantero a acudir a otras versiones donde este suceso queda explicitado. Este sería el caso de la versión del Texto de las Pirámides en la que el suceso queda referido explícitamente: «Tu hermana Isis viene a ti regocijada de tu amor; tú la colocas sobre tu falo y tu simiente penetra en ella» ${ }^{37}$. Esta misma escena también se refleja en los relieves e inscripciones que adornan las paredes del templo del rey Sethy I en Abidos en los que "Osiris able to raise one arm to his head held by Isis and with the other to grasp his phallus so as to arouse himself to orgasm. Isis then pressed herself onto the phallus, thus becoming impregnated ${ }^{38}$.

Para Mantero, el mito de Isis y Osiris es el triunfo de la invención -«Isis y Osiris que inventa la vida»-, «del principio inmortal y divino», frente a la caducidad de la muerte ${ }^{39}$. Isis se describe como el elemento activo, la agente de la regeneración post-mortem de Osiris y de la concepción de Horus. A su vez, Horus, «vástago de sol», representa la continuación de Osiris y la superación de la muerte de este. Por este motivo, Mantero prefiere las versiones donde el momento de la creación se manifiesta frente a aquellas otras, como la de Plutarco, que escatiman este punto del relato.

Siguiendo a Ivanne Rialland ${ }^{40}$, aunque Mantero crea un texto nuevo, el sustrato mítico se respeta siguiendo su estructura, «archétypocritique» ${ }^{41}$. Pero, al mismo tiempo, su perspectiva o, si preferimos, «l'interprétant» ${ }^{42}$, desde el que Mantero enfoca el mito en su poema, responde a un planteamiento metapoético donde la palabra lírica se revela como creación original. Lo significativo, en este caso, es que «Pantomima» permite hacer explícita la concepción fundacional, como ya hemos visto, pero también transformativa que comparten mito y poesía. Incidiré algo más sobre este último aspecto.

Por un lado, Mantero concibe el mito egipcio como base de «Pantomima», pero no repite su argumento sino que lo transforma. Su relato lírico se concibe como un formante

\footnotetext{
${ }^{35}$ Ibid., p. 159.

${ }^{36}$ Plutarco, op. cit., p. 90, $\$ 17$ 357E.

${ }^{37}$ Champdor, Albert, El libro egipcio de los muertos, Buenos Aires, Edaf, 2006, p. 38.

${ }^{38}$ Clark, R. T. Rundle, Myth and symbol in Ancient Egypt, London, Thames and Hudson, 1991, pp. 3233.

${ }^{39}$ Piulats Riu, Octavi, Egiptosophia. Relectura del mito al logos, Barcelona, Kairós, 2006, p. 168.

${ }^{40}$ Ivonne Rialland, «Mythe et hypertextuality», Fábula, 28 de abril de 2005. https://www.fabula.org/ atelier.php?Mythe_et_hypertextualit\%26eacute\%3B (fecha de consulta: 25/04/2021).

${ }^{41}$ Véase Genette, Gérard, op. cit.

${ }^{42}$ Riffaterre, Michael, op.cit., p. 134.
} 
elidido en las versiones anteriores. Esta elección exhibe su distanciamiento teórico con Jean-François Lyotard en cuanto al mito ${ }^{43}$ : «No estoy de acuerdo con Lyotard cuando dice que la narración mítica es "idéntica repetición". No. El auténtico escritor toma el mito como base e interpretación, no como argumento reproductivo» ${ }^{44}$.

Pero, por otro lado, en «Pantomima», Mantero transforma a Isis y la coloca como el arquetipo del eterno femenino ${ }^{45}$, figura que funciona a modo de vínculo entre la consciencia del yo y el inconsciente colectivo: «Su búsqueda para reunir las partes de su esposo refleja el proceso de diferenciación y relación de las partes a la psique humana con el objeto de lograr una integración total de consciencia e inconsciente y alcanzar la revelación de la inmortalidad $»^{46}$. De este modo, para Mantero, el mito de Isis y Osiris aparece como la base de su relato sobre el proceso de integración con el sí-mismo, siguiendo la terminología junguiana, e Isis se establece como la personificación que conduce a la unidad de lo consciente y lo inconsciente. Se trasluce de este modo la influencia teórica procedente de la psicología analítica en el planteamiento poético de Mantero donde la poesía y también el mito se definen como material simbólico en el que convergen el conocimiento consciente y el que procede del inconsciente colectivo ${ }^{47}$. En este sentido, de acuerdo con el esquema interpretativo del mito que propone Pierre Brunel, es posible considerar este texto como un ejemplo de «flexibilité» donde el mito se adapta al nuevo texto, pero el elemento mítico aparece de forma resistente ${ }^{48}$.

\section{5. «El heChizo de Iris» de José MARÍa Merino}

José María Merino ha explorado el mito en diversas narraciones entre las que destacan El caldero de oro, La orilla oscura y El centro del aire, que agrupó bajo el título Las novelas del mito. Sin embargo, más allá de esta tríada, en la obra de Merino el material mítico aparece de manera recurrente, sobre todo, apoyado en el mito del doble. Merino ha manifestado en ensayos y en un gran número de novelas y cuentos su fascinación por este mito que proviene de sus lecturas de El Quijote de Miguel de Cervantes y de Niebla de Miguel de Unamuno ${ }^{49}$. La atracción por el mito del doble, que se percibe en el universo narrativo de Merino, reside en su convicción de que el ejercicio literario se sustenta en el desdoblamiento del autor en la ficción.

${ }^{43}$ Lyotard, Jean-François, op. cit., p. 67.

${ }^{44}$ Mantero, Manuel, «Poética y antología personal», Salina, 15 (2001), p. 27.

${ }^{45}$ Véase Jung, Carl Gustav, Arquetipos e inconsciente colectivos.

${ }^{46}$ Mantero, Manuel, Como llama en el diamante (Poesía completa) 3, Sevilla, Fundación El Monte, 1996, p. 32 .

${ }^{47}$ Véase Jung, Carl Gustav, Símbolos de transformación.

${ }^{48}$ Brunel, Pierre, Mythocritique. Théorie et parcours, p. 79.

${ }^{49}$ Sin afán de exhaustividad, el mito del doble aparece en el ensayo «Ecos y sombras del delirio quijotesco y Doble del doble» (2008), y las novelas de José María Merino, Andrés Choz, La orilla oscura, No soy un libro/Los trenes del verano y El heredero, y en los cuentos «El nacimiento en el desván», «El soñador» y «Expiación» (los tres recogidos en Cuentos del reino secreto, 1982), «El derrocado» (Cuentos del Barrio del Refugio, 1994), «La dama de Urz», «El hechizo de Iris» (ambos en Cuatro nocturnos, 1999), «El fumador que acecha», «Papilio Síderum» (ambos en Cuentos de los días raros, 2005), y «El duplicado» (Aventuras e invenciones del profesor Souto, 2017). 
En esta línea habría que situar el cuento largo o novela corta «El hechizo de Iris» de la colección Cuatro nocturnos (1999) ${ }^{50}$. «El hechizo de Iris» narra el adolescente y confuso amor de verano de Javier e Iris, una chica que simula tener una hermana gemela, Laura. Javier, protagonista y voz narrativa de este cuento, recuerda su amor con Iris una vez que se encuentra años más tarde con la que cree que es su hermana gemela, Laura. A causa de este hilo argumental, «El hechizo de Iris» ha sido mayoritariamente acogido por la crítica desde el concepto de la falsa duplicidad ${ }^{51}$. Esto mismo lo señaló el propio autor que confesó que la trama de esta narración se sustenta en un personaje femenino que aparece duplicado a ojos del narrador autodiegético ${ }^{52}$.

Según mi análisis, este relato también incorpora en su base narrativa mitemas del mito de Isis y Osiris tales como la recomposición de los fragmentos del yo, aunque José María Merino evite la alusión directa al relato del intertexto ideal, salvando la similitud equívoca entre «Isis» e «Iris». Así, este cuento se concibe por Merino obviando el propósito de reescritura que se apreciaba en los dos ejemplos anteriores. Sin embargo, como ya aludía Joaquín Marco, en una de las primeras reseñas que se publicaron de este cuento, existe en este relato una dimensión alegórica que dirige al lector a una reflexión similar, aunque actualizada, a la que conducía el mito de Isis y Osiris ${ }^{53}$. Es por ello que, en este caso, la perspectiva metodológica de la mitocrítica de Durand - «análisis del trasfondo mítico de un texto literario» ${ }^{54}$ adquiere una especial relevancia. En «El hechizo de Iris» los mitemas de la recomposición y la resurrección del mito están presentes, pero lo hacen de manera latente, disimulados por contenidos alejados ${ }^{55}$, y transformados según la sensibilidad contemporánea, a diferencia de las apariciones del mito en Lorca y Mantero que se establecían de forma manifiesta ${ }^{56}$.

Si se avanza en el relato se observa que Javier, después de reencontrarse con Iris-Laura, empieza a cambiar de hábitos de vida y recobra la amistad con las personas que formaban parte de su adolescencia. Javier se reconvierte y reconstruye una identidad pasada de la que se había despojado y recobra los recuerdos del primer amor o la inocencia de la adolescencia: «Entonces comprendí que todo lo que pasó forma parte inalterable de lo que soy, y que uno debe acostumbrarse a las piezas sueltas que lleva dentro ${ }^{57}$. Como Osiris, Javier recompone sus pedazos, que no son corporales sino espirituales, y renace, no a través del linaje y del nacimiento de Horus como ocurría en el mito, sino a partir de la génesis de una nueva mismidad. De igual forma, en ambos relatos, el personaje femenino Iris/Isis se establece como el elemento que deshace la muerte/olvido - «Pues si la muerte es el gran olvido, todo olvido reiterado es una pequeña muerte, un pedazo de muerte que se anticipa ${ }^{58}-y$ propicia el génesis.

\footnotetext{
${ }^{50}$ Merino, José María, Cuatro nocturnos, Madrid, Alfaguara, 1999.

${ }^{51}$ Noyaret, Natalie, "El hechizo de Iris: la duplicidad elevada a extraños niveles», en Andrés-Suárez, Irene y Casas, Ana (ed.), José María Merino. Actas del gran seminario de la Universidad de Neuchâtel. Cuadernos de narrativa 6, 2005, pp. 249-265; Martínez Arnaldos, Manuel y Pujante Segura, Carmen, «José María Merino, un escritor contemporáneo de novelas cortas (sobre El lugar sin culpa y otros nocturnos), Actio nova. Revista de teoría de la literatura y literatura comparada, 0 (2016), pp. 196-219.

${ }^{52}$ Merino, José María, «La reescritura del mito del doble en los relatos fantásticos de José María Merino», Herrero Cecilia, Juan y Morales Peco, Montserrat (ed.), Reescrituras de los mitos en la literatura, Castilla-La Mancha, Ediciones de la Universidad de Castilla-La Mancha, 2008, p. 473.

${ }^{53}$ Marco, Joaquín, «Reseña a Cuatro nocturnos», El Cultural, 14 de marzo de 1999.

${ }^{54}$ Herrero Cecilia, Juan, op. cit., p. 71.

${ }^{55}$ Durand, Gilbert, De la mitocrítica al mitoanálisis, p. 345.

${ }^{56}$ Durand, Gilbert, Mitos y sociedades. Introducción a la mitología, p. 139.

${ }^{57}$ Merino, José María, Cuatro nocturnos, p. 76.

${ }^{58}$ Ibid., p. 72.
} 
La metamorfosis de Javier, que se incorpora en esta narración a través del mito de Isis y Osiris, conecta con los principios narrativos de Merino donde la transformación se alza como uno de los motores principales de su obra. Como bien apunta Asunción Castro Díez, la metamorfosis en la narrativa de Merino se percibe como un proceso recurrente que armoniza la totalidad de su obra y donde se instalan la mayor parte de los mitos. El mito se advierte como una herramienta catalizadora que permite dotar de normalidad a lo excepcional gracias a su carácter arquetípico universal y colectivo, si atendemos a la idea junguiana del mito como estructura que forma parte del inconsciente colectivo. En este caso, el mito de Isis y Osiris regulariza la transformación psíquica y el mito del doble convierte en ordinaria la duplicidad del personaje de Iris/Laura en pos de materializar la metamorfosis de Javier en el relato.

Si se analiza este cuento bajo la lupa de la división tripartita de Pierre Brunel, es posible asimilarlo al concepto de «irradiation», en el que no es necesario explicitar el mito y tan solo con actualizar uno de sus rasgos, en este caso, el poder de Isis para propiciar la metamorfosis, el relato subordina sus elementos a este eje y, a partir de entonces, compone su desenlace ${ }^{59}$. El funcionamiento del mito de Isis y Osiris en esta novela corta también puede explicarse a través de la noción de mitema latente propuesta por Gilbert Durand ${ }^{60}$. Merino no manifiesta ningún estereotipo del mito y prefiere dotar al relato literario de señales implícitas como la equívoca nominación del personaje femenino, Iris/Isis, y su capacidad de incitar la génesis psíquica en el personaje masculino de esta narración. Al privilegiar el mitema de la resurrección por encima del resto de los componentes del mito, también es posible asociar este caso con el procedimiento que Durand denomina cisma, ya que del mito de Isis y Osiris solo se utiliza un mitema y se suprimen el resto de los axiomas que definirían el relato mítico ${ }^{61}$.

\section{ConClusión}

Según este repaso por la recepción del mito de Isis y Osiris en la literatura española contemporánea a través de las obras de Federico García Lorca, Manuel Mantero y José María Merino, se observa la presencia de distintas fuentes primigenias desde las que se orienta la actualización del mito y el uso de distintas prácticas de reescritura. De este modo, mientras Lorca y Merino optan por vincular su relato con el de Plutarco, el más repetido en la cultura occidental, Mantero indaga en pasajes del mito de Isis y Osiris recogidos en versiones anteriores como en El texto de las Pirámides. De igual forma, las manipulaciones que se realizan de este mito en estos tres ejemplos literarios también presentan rasgos diferenciadores. Mientras Lorca y Mantero optan por señalar de forma manifiesta personajes y argumentos del relato del mito, Merino prefiere recurrir a la referencia latente para que el mito opere en un plano secundario de la narración. La modulación del grado de aparición del mito en el texto contemporáneo también ofrece un tratamiento distinto en Lorca, Mantero y Merino. Mientras que el mito de Isis y Osiris emerge en «Balada de un día de julio» de Lorca y contamina en su totalidad el curso del poema, en «Pantomima» el relato mítico se adapta a la reflexión lírica que Mantero emprende en este texto sobre los planos de consciencia de la psique y, finalmente, la pulsión de Isis que

\footnotetext{
${ }^{59}$ Brunel, Pierre, Mythocritique. Théorie et parcours, pp. 81-86.

${ }^{60}$ Durand, Gilbert, Mitos y sociedades. Introducción a la mitología, p. 345.

${ }^{61}$ Ibid., p. 145.
} 
brota en el personaje de Iris/Laura provoca que el mito irradie significaciones como la reconversión en «El hechizo de Iris» de Merino.

Frente a estos elementos distinguidores, se observa asimismo en estos tres casos una misma dirección de reescritura. Lorca, Mantero y Merino coinciden en distinguir en Isis la capacidad de mediación que permite superar la muerte y el olvido y proveer la trascendencia del ser. En los tres ejemplos estudiados, la presencia de Isis permite reconvertir la identidad del Otro y, como vimos anteriormente, en este mitema de metamorfosis, es en el que reside el sentido primigenio del mito egipcio de Isis y Osiris. Isis se presenta, entonces, como esa otra mismidad, que posibilita un nuevo génesis. Los polos de Isis y Osiris son concebidos en estas reescrituras del mito como seres próximos, complementarios, dependientes, cooperantes y semejantes. De ahí que la relación fraternal-marital del mito deba entenderse en términos de igualdad y de dualidad. No somos si no es con el Otro, o, si preferimos, somos gracias al Otro. Por ello, la viudita busca desesperadamente a su conde Laurel, Isis y Osiris en el poema de Mantero hacen el amor para vengarse de la muerte o Iris llega a la vida de Javier para que reconvierta su identidad asumiendo su pasado.

En definitiva, en estos ejemplos de la literatura española contemporánea, el tándem que establecen Isis y Osiris se manifiesta desde la hermandad, si entendemos este concepto no sólo desde la pura relación fraternal, elemento vigente en el mito egipcio, sino como unión de voluntades, correspondencia entre dos personas y agrupación en busca de un mismo propósito.

\section{REFERENCIAS BIBLIOGRÁFICAS}

Aguilar Fernández, Rosa María, «El mito griego en la poesía de García Lorca», Cuadernos de filología clásica: estudios griegos e indoeuropeos, 8 (1998), pp. 75-102.

Álvarez de Miranda, Ángel, La metáfora y el mito, Madrid, Ediciones Taurus, 1961.

Arséntieva, Natalia, «Orígenes y estructura y principales aspectos de la cosmología mitopoética de García Lorca», Camacho Rojo, José María (ed.), La tradición clásica en la obra de Federico García Lorca, Granada, Universidad de Granada, 2006, pp. 249-309.

Barnette, Douglas W., «Manuel Mantero y el proceso poético», Anthropos: Boletín de información y documentación, 116 (1991), pp. 27-31.

Brunel, Pierre (dir.), Dictionnaire des mythes littéraires, Éditions du Rocher, Bertrand, 1988.

—, Mythocritique. Théorie et parcours, Paris, Presses Universitaires de France, 1992.

Camacho Rojo, José María (ed.), La tradición clásica en la obra de Federico García Lorca, Granada, Universidad de Granada, 2006.

Carmona Vázquez, Antonia, Coincidencias de lo trágico entre Eurípides y Federico García Lorca, Alcañiz, Ediciones del Laberinto, 2003.

-, «Elementos míticos en el teatro de Eurípides y F. García Lorca», Calamus Renascens: revista de humanismo y tradición clásica, 2 (2001), pp. 23-41.

Clark, R. T. Rundle, Myth and symbol in Ancient Egypt, London, Thames and Hudson, 1991.

Crespo, Ángel, «Ética y estética en la poesía de Manuel Mantero», Anthropos: Boletín de información y documentación, 116 (1991), pp. 32-41.

Champdor, Albert, El libro egipcio de los muertos, Buenos Aires, Edaf, 2006.

García Gual, Carlos, Diccionario de mitos, Barcelona, Planeta, 1997.

Durand, Gilbert, Mitos y sociedades. Introducción a la mitología, Buenos Aires, Editorial Biblos, 2003. 
—, De la mitocrítica al mitoanálisis: figuras míticas y aspectos de la obra, Barcelona, Anthropos, 1993.

Faulkner, Raymond O., The ancient Egyptian pyramid texts, Oxford, Clarendon Press, 1969.

Fernández Delgado, José Antonio y Pordomingo Pardo, Francisca, «Introducción», en Plutarco, Obras morales y de costumbres (Moralia) 6, Madrid, Gredos, 1995, pp. 7-86.

García Lorca, Federico, Obras completas: poesía, Barcelona, Galaxia Gutenberg, 1997.

Genette, Gérard, Palimpsestes. La littérature au second degre, Paris, Éditions du Seuil, 1992.

Herrero Cecilia, Juan, «El mito como intertexto: la reescritura de los mitos en las obras literarias», Çedille. Revista de estudios franceses, 2 (2006), pp. 58-76.

Jung, Carl Gustav, Símbolos de transformación, Barcelona, Paidós, 2005.

-, Arquetipos e inconsciente colectivos, Barcelona, Paidós, 2009.

Lévi-Strauss, Claude, Antropologie structurale, Paris, Plon, 1958.

-, Myth and meaning, Toronto, University of Toronto, 1978.

Lichtheim, Miriam, Ancient Egyptian literature. A book of readings 1, Berkeley, University of California Press, 1973.

Lyotard, Jean François, The inhuman. Reflections on time, California, Stanford University Press, 2008.

Mantero, Manuel, Crates de Tebas, Ferrol, Esquío, 1980.

—, Memorias de Deucalión, Barcelona, Plaza \& Janés, 1982.

-, "Autopercepción intelectual de un proceso histórico: autobiografía intelectual y cronología», Anthropos: Boletín de información y documentación, 116 (1991), pp. 11-26.

—, Fiesta, Madrid, Endymion, 1995.

-, Como llama en el diamante (Poesía completa) 3, Sevilla, Fundación El Monte, 1996.

—, «Poética y antología personal», Salina, 15 (2001), pp. 26-37.

Marco, Joaquín, «Reseña a Cuatro nocturnos», El Cultural, 14 de marzo de 1999.

Martínez Arnaldos, Manuel y Pujante Segura, Carmen, «José María Merino, un escritor contemporáneo de novelas cortas (sobre El lugar sin culpa y otros nocturnos)», Actio nova. Revista de teoría de la literatura y literatura comparada, 0 (2016), pp. 196-219.

Merino, José María, Cuatro nocturnos, Madrid, Alfaguara, 1999.

-, «La reescritura del mito del doble en los relatos fantásticos de José María Merino», en Herrero Cecilia, Juan y Morales Peco, Montserrat (ed.), Reescrituras de los mitos en la literatura, Castilla-La Mancha, Ediciones de la Universidad de Castilla-La Mancha, 2018, pp. 467-480.

Newton, Candelas, Lorca, una escritura en trance: Libro de poemas y Diván del Tamarit, Amsterdam / Philadelphia, John Benjamins Publishing Company, 1972.

Noyaret, Natalie, "El hechizo de Iris: la duplicidad elevada a extraños niveles», Irene Andrés-Suárez y Ana Casas (ed.), José María Merino. Actas del gran seminario de la Universidad de Neuchâtel. Cuadernos de narrativa 6, 2005, pp. 249-265.

Pecci Tenrero, Hipólito, «Isis, la Gran Maga», Espacio, tiempo y forma, 15 (2004), pp. 11-26.

Piulats Riu, Octavi, Egiptosophia. Relectura del mito al logos, Barcelona, Kairós, 2006.

Plutarco, Obras morales y de costumbres (Moralia) 6, Madrid, Gredos, 1995.

Rialland, Ivonne, «Mythe et hypertextuality», Fábula, 28 de abril de 2005. https://www.fabula.org/ atelier.php?Mythe_et_hypertextualit\%26eacute\%3B (fecha de consulta: 25/04/2021).

Riffaterre, Michael, «Sémiotique intertextuelle: l'interprétant», Revue d'esthétique, 1-2 (1979), pp. 128150.

Santamaría Canales, Israel, «Isis a través de los textos: el culto isíaco en la literatura grecolatina de época imperial», Ilu. Revista de ciencias de la religiones, 20 (2015), pp. 231-248.

Siganos, André, Le Minotaure et son mythe, Paris, Presses Universitaires, 1993.

Tijeras, Eduardo, «Hacia García Lorca por las imágenes del agua», Cuadernos Hispanoamericanos, 433434 (1985), pp. 89-102. 